\title{
El meme, instrumento político de comunicación viral en la campaña presidencial colombiana 2018
}

Revista Latinoamericana de Economía y Sociedad Digital

Issue 2, agosto 2021

Autores: William David Suárez Acosta(D) Víctor García-Perdomo(iD)

DOI: $10.53857 / \mathrm{XKOI1616}$

Publicado: 2 febrero, 2022

Recibido: 20 marzo, 2021

Cita sugerida: Suárez Acosta, William David y Víctor García-Perdomo (2021) "El meme, instrumento político de comunicación viral en la campaña presidencial colombiana 2018” en Revista Latinoamericana de Economía y Sociedad Digital, Issue 2

Licencia: Creative Commons Atribución-NoComercial 4.0 Internacional (CC BY-NC 4.0)

Tipo: Estudio de caso

Palabras clave: framing de medios, humor político, Memes, Twitter

\section{Resumen}

Este estudio analiza las características de los encuadres (visuales y textuales) de los memes compartidos en Twitter que lo convirtieron en un instrumento de comunicación política en la campaña presidencial colombiana de 2018. Con un análisis de contenidos, se analizaron 358 memes utilizando un libro de código y como marco teórico los postulados de viralidad, humor memético y encuadres de medios (framing) del perfil de los candidatos para comprender las características del meme político y su transmisión en Twitter durante una contienda electoral. Los resultados muestran una tendencia a atacar las debilidades de los opositores más que a defender las ideas del candidato propio.

\section{Abstract}

This study analyzes the characteristics and frames (visual and textual) of memes shared on Twitter that became forms of political communication in the 2018 Colombian presidential campaign. Using multimodal content analysis and taking into consideration variables such 
as virality, humor, media frames and users' intention, 358 memes were analyzed to evaluate the most effective ways to spread political memes on that social media platform. Results show a tendency to attack the weakness of the opposite candidate rather than to defend the ideas of the own candidate.

\section{Resumo}

Este estudo analisa as características dos frames (visuais e textuais) dos memes compartilhados no Twitter que o tornaram um instrumento de comunicação política na campanha presidencial colombiana de 2018. Com uma análise de conteúdo, 358 memes foram analisados usando um livro de código e como referencial teórico os postulados de viralidade, humor memético e enquadramento midiático do perfil do candidato para compreender as características do meme político e sua transmissão no Twitter durante uma disputa eleitoral. Os resultados mostram uma tendência de atacar as fraquezas dos adversários ao invés de defender as próprias ideias do candidato.

\section{Introducción}

La presente investigación está enmarcada dentro del campo de la comunicación pública, particularmente en la interacción online de las audiencias a través del meme como forma de comunicación política digital. Durante los últimos años, la proliferación de memes a través de la red ha sido generada como respuesta a diversos acontecimientos políticos (Kuntsman \& Raji 2012) y les ha permitido a las audiencias reaccionar en la red, en tiempo real, sobre una determinada coyuntura social, política o económica (Freelon \& Karpf 2015).

La memética ha sido considerada como una idea o concepto expresado, generalmente, de manera gráfica y que viaja con facilidad a través de las redes sociales (Eizaguirre, 2016, p. 1257). Sus principales temáticas comprenden el humor, el conflicto, el sexo y la política. Dichas cualidades interactúan entre sí mediante palabras e imágenes que circulan profusamente en la red (Jurgenson, 2012). El activismo cívico online del meme tuvo uno de sus puntos álgidos en septiembre de 2011 durante las protestas populares denominadas Occupy Wall Street, una reacción de numerosos grupos sociales a la crisis financiera y económica en Estados Unidos. Allí, millones de norteamericanos usaron al meme como herramienta satírica y de humor político para incentivar el debate público y participar de las discusiones políticas y sociales derivadas de la crisis económica y la debacle del mercado (Milner, 2013, p. 2359).

En Colombia, la llamada “Ola Verde”, puede considerarse como el principal antecedente del uso de las redes sociales durante unas elecciones presidenciales. En 2010, los políticos Antanas Mockus y Sergio Fajardo se consolidaron como la fórmula presidencial que hacía 
frente a la prolongación del gobierno de Álvaro Uribe en cabeza del entonces candidato y ex ministro de defensa Juan Manuel Santos. Gracias a la creatividad de los usuarios que, por medio de Facebook y Twitter defendían las ideas de los aspirantes políticos, el movimiento creció y generó esperanza para aquellos que estaban descontentos con las políticas uribistas. A pesar de que la euforia en las redes no se reflejó en las urnas, mostrando una vez más que lo que ocurre en las plataformas no necesariamente coincide con la participación política real, el antecedente marcó el comienzo de la contienda online.

Actualmente, el 63\% de la población colombiana tiene acceso a Internet y los candidatos, cada vez más conscientes de este fenómeno, llevan sus estrategias políticas a la red para promover sus ideas (We Are Social, 2020). Dentro de la idiosincrasia colombiana, este fenómeno, no solo ha sido usado para resemantizar situaciones de la cultura, sino que, eventualmente, pasó a tener un protagonismo mediático en el ámbito político gracias a la rapidez con la que se reproducen los mensajes y la creatividad que promueven sus contenidos (Villar, 2014). Sin embargo, para comprender la inusitada importancia del meme en la sociedad actual, es menester señalar que su divulgación obedece al auge de las redes sociales y las tecnologías digitales. Dichas plataformas han influido de manera determinante en la evolución del lenguaje y en las nuevas formas de comunicación discursiva que las audiencias digitales utilizan para interactuar entre sí (Espinosa, Vargas, \& Franco, 2015). El impacto de las nuevas tecnologías de la información ha trascendido las fronteras territoriales de tal forma que, en tiempo real, los usuarios online utilizan el meme como una respuesta cultural a eventos mediáticos que son altamente visibles (Yang, 2016). En redes sociales como Twitter y Facebook el meme reside con un alto poder de difusión mediática, facilitando el debate político a través de las redes de medios participativos (Milner, R. M. 2013).

Utilizando framing y estudios de memética como marco conceptual, la presente investigación busca analizar las características particulares de los memes que circularon durante la campaña presidencial 2018 en Colombia, a fin de entender la conceptualización política que se hace de los candidatos y las interacciones que generaron estas imágenes entre los usuarios de la red social Twitter. Algunos de los principales hallazgos muestran que imágenes fijas con texto que representan a los candidatos como perdedores seguros y las relacionadas con corrupción son más recurrentes en la muestra de 358 memes analizados. También, memes que invitan a la conversación o al juego humorístico son más comúnmente elaborados y compartidos por los usuarios en red. Los ataques a los candidatos contrarios más que la defensa del candidato propio muestran el nivel de polarización de la red y, además, las constantes alusiones a la corrupción reflejan la desconfianza hacia la política y los políticos en general durante la campaña. 


\section{Marco Teórico}

El meme fomenta la participación política y el activismo cívico alrededor de temas coyunturales que conforman la agenda política de la sociedad (Milner, 2013; Yang, 2016). El término, acuñado por Richard Dawkins en 1976 con su obra El Gen Egoísta, definió al meme como "un sustantivo que conlleva la idea de una unidad de transmisión cultural, o una unidad de imitación" (1976: 218). Desde su conceptualización en los 70s, la noción sobre el término 'meme' ha evolucionado hasta nuestros días como un elemento multimedia que se ha popularizado gracias a la democratización de los medios digitales.

La evolución e influencia de los memes en la sociedad ha puesto en tela de juicio su papel informativo porque, aunque han sido comparados con la caricatura crítica, muchos de los memes replicados en la arena política se reproducen de manera automática y su credibilidad generalmente se da por sentada cuando, en muchos casos, su veracidad y origen es dudoso (Ratkiewiez et al. 2011). También, se ha reportado la participación de grupos políticos, gabinetes de prensa, movimientos sociales, granjas de información maliciosa y automatización para afectar con imágenes que circulan rápidamente por las redes el entendimiento social de un fenómeno o los procesos electorales en diversos países, muchas veces en contra de los principios democráticos y acentuando guerras propagandísticas (The Guardian, 2016). A pesar de ello, los movimientos sociales o antiestablecimiento han utilizado el meme como un elemento crítico en la sociedad y le han atribuido características que lo hacen fundamental para el entendimiento de ciertos fenómenos en las comunidades. El proceso comunicativo del meme, además de ser replicable es de resemantización; es decir, desencadena un proceso por el cual se le da un nuevo valor de significado a un vocablo preexistente que, de acuerdo con ciertas características, se vuelve viral en la red.

\section{El meme en la arena política}

Estudios sobre la memética han encontrado diversas influencias de estas imágenes y mensajes en el ámbito político. Por ejemplo, Ross y Rivers (2017) analizaron las características visual-discursivas de los memes durante las elecciones presidenciales de 2016 entre Hillary Clinton y Donald Trump y encontraron que los memes eran un factor negativo y deslegitimador de la conducta de los candidatos. Roos y Rivers concluyeron que los prosumidores de los memes analizados transmitían su postura ideológica mediante todo tipo de referencias a la cultura digital para construir nuevos significados generalmente contrarios al statu quo. A su vez, Martínez y Piñeiro (2016), quienes analizaron el uso del meme en el discurso digital de los partidos políticos españoles en Twitter durante el Estado de la Nación en España en 2015, revelaron que el meme reforzaba las ideas defendidas por el líder de un partido, mientras que atacaba la trayectoria y propuestas de los otros grupos políticos, influenciando la reputación de los protagonistas en la esfera política de una nación. Mina (2014) concluyó que los memes deben considerarse actos políticos importantes en sí mismos en contextos autoritarios y censurados como los de China. Para la autora Mina, 
los memes son un elemento de cambio social, una pequeña reclamación de poder contra los medios de comunicación estatales chinos. Las imágenes desafían a los medios estatales oficiales a través del remix y el humor y se basan en las normas de una cultura más amplia que alienta a otros a participar y unirse a la comunidad.

La inestabilidad del meme como unidad comunicativa política, sin embargo, ha despertado la preocupación de algunos investigadores. Por ejemplo, Kuntsman y Raji (2012) señalan que los memes constituyen una forma de capital cultural que es necesario para afirmar una voz legítima, pero sostienen que son unidades culturales inherentemente inestables y que la búsqueda de innovación conduce a una constante insatisfacción con el mensaje. En algunas formulaciones, estas imágenes tienden a hacer eco de las voces de los grupos privilegiados; otros facilitan lo que Milner (2012) describe como un discurso "polivocal”, incorporando varios puntos de vista, incluyendo los marginales y subversivos que protestan contra la corrupción gubernamental (Bennett \& Segerberg, 2012). Por su parte Silvestri (2014) sostiene que quizá el aporte más significativo del tratado de Shifman (2014) sobre los memes es que pueden servir como caballo de Troya para la comunicación política y potencialmente ser el campo de juego para diversos actores políticos. Shifman (2014) sostiene que, gracias a la aparición de los nuevos medios, "la percepción de lo que constituye la participación política se ha ampliado para incluir prácticas mundanas tales como comentar blogs políticos y publicar bromas sobre políticos" (p.120). Es en este sentido que autores como Silvestri, concluyen que "los memes de Internet representan otra forma de que los ciudadanos comunes reivindiquen el espacio público al cabalgar la cultura popular" (p.199). En su estudio sobre Occupy Wall Street, Milner (2013) concluyó que al momento de generar un meme que aporte a la creación de la crítica política, los usuarios deben encontrar el equilibrio entre la fijeza y la novedad; es decir, los creadores de meme están obligados a saber qué aspectos de este deben mantenerse sin cambios y dónde pueden expresar originalidad.

En el contexto latinoamericano, los estudios sobre el meme también han llegado a conclusiones relevantes respecto a su influencia o connotación política. En un número especial dedicado al meme, la revista mexicana Virtualis (editado por Pérez Salazar, 2020) muestra cómo estas imágenes transferibles en red no solo representan una participación política basada en la transgresión (Ramírez Moge \& Siles, 2020) sino que en ciertos contextos generan discursos persuasivos alrededor de los candidatos políticos durante las elecciones (Gutiérrez Vidrio \& Reyna Ruiz, 2020), o sirven para construir la imagen de una figura pública con referentes ideológicos en medio de una crisis sanitaria (Bañuelos \& Cerrillo, 2020) o perpetúan estereotipos alrededor de la violencia de género (GarcíaGonzález \& Bailey, 2020), el racismo y el clasismo latinoamericanos (Chavarría-Cruz, 2020), utilizando como recurso la sátira y el humor. En el contexto de Colombia, Espinosa, Vargas y Franco (2015), analizando la retórica de memes alusivos al paramilitarismo en durante un debate en el Congreso, subrayan en su estudio la capacidad de los usuarios de utilizar elementos culturales, visuales y humorísticos para resistir el poder político y consideran al meme como un medio liberador que sobrepasa la censura y la autoridad de los estamentos 
oficiales. Mercado y Scargiali (2020), al investigar los memes que circularon por las redes entre 2015 y 2019 sobre los movimiento políticos de derecha de Brasil y Argentina, llegaron a la conclusión de que las imágenes promueven agendas públicas de debate y expresan el clima político de cada coyuntura utilizando el humor. Finalmente, Collado Campos (2020) analizó el caso de los memes del ex presidente mexicano Enrique Peña Nieto y concluyó que los usuarios utilizan estas imágenes para ridiculizar el discurso hegemónico del mandatario, pero que su naturaleza es tan fluida que impide la formación de movimientos estables de protesta a su alrededor. Vemos, entonces, que diversos estudios muestran que el meme tiene una función política relevante en la red.

\section{Framing, marcos y mensajes visuales}

A los estudios sobre el meme político, esta investigación añade la conceptualización teórica del framing o los marcos para entender cómo esas imágenes contienen ciertas ideas. Los "marcos o encuadres" son aquellos esquemas utilizados por las audiencias y por los productores de contenidos con el fin de ofrecer un sentido a los problemas y eventos de coyuntura (Gitlin 1980, Lyombe 1999, Pan \& Kosicki 1993). Reese (2001) define los encuadres como aquellos "principios organizadores socialmente compartidos y persistentes en el tiempo, que funcionan simbólicamente para estructurar el mundo social de modo significativo" (p. 11). Para Goffman (1974), el valor agregado de este proceso radica en la potestad que los comunicadores tienen de enfocarse en los aspectos principales de un tema, dejando por fuera aquellos que no son de su interés o que no refuerzan sus ideales. Durante el proceso, los comunicadores enmarcan todo tipo de mensajes de una manera más accesible a las audiencias. Dichos marcos influyen en las ideas y percepciones que el público tiene sobre un concepto o situación en general (Schudson, 2003).

\section{Encuadre de medios del perfil de los candidatos}

En los estudios de framing algunos autores han identificado marcos genéricos y marcos específicos con relación a distintos contextos culturales y coyunturas sociales (Aruguete, 2011; De Vreese, 2005). Los frames genéricos representan niveles de conceptualización estables que pueden ser aplicados a distintos asuntos noticiosos o de política pública, tanto desde una perspectiva de estudio sociológica como sicológica (Mahl \& Guenther, 2021; Semetko \& Valkenburg, 2000; Entman, 1993; Gamson \& Modigliani, 1989). De Vreese (2005), particularmente, ha resaltado el uso de marcos genéricos en los estudios centrados en la cobertura política, en las campañas electorales y en hechos noticiosos inherentes a las convenciones del periodismo.

De gran utilidad para este estudio resulta la aproximación de Grabe y Bucy (2009), quienes analizaron el cubrimiento televisivo de campañas políticas e identificaron tres tipos de marcos genéricos usados por los medios de comunicación para transmitir las noticias electorales generales y cubrir a los candidatos. Los marcos propuestos fueron el candidato ideal, el candidato perdedor seguro y el activista populista (Grabe \& Bucy, 2009, p. 86). Para estos autores, los candidatos presidenciales parecen "usar" los marcos visualmente 
construidos para que el electorado acepte implícitamente dicha forma de representación. Sin embargo, sugieren que los problemas de los políticos para abordar diversos temas o las dificultades que esto tengan para preservar su impacto visual en los debates televisivos pueden generar dudas y poca confiabilidad en el electorado (p. 86).

El candidato ideal es representado como un individuo que proyecta una imagen de autoridad, poder y control. Cumple la imagen ideal de un líder posándose con otros, luce serio, tiene compasión por sus seguidores y parece un estadista (Grabe \& Bucy, 2009). Por su parte, el activista populista se le representa como "uno más del pueblo", en camisa, con mangas arremangadas o con ropa ordinaria, haciendo cosas normales y visitando fábricas o granjas (Grabe \& Bucy, 2009). El perdedor seguro es exactamente como suena. El candidato manifiesta movimientos faciales inapropiados como, por ejemplo, fruncir el ceño en momentos de interacción con el electorado, se muestra en un escenario con grupos pequeños o desaprobadores, presenta un aspecto ridículo y tiene un talante inapropiado para el ambiente en el cual es fotografiado (Grabe \& Bucy, 2009).

Foster (2014) afirma que, en 2012, candidatos como Barack Obama en Estados Unidos tardaron poco más de cuatro años desarrollando un encuadre de medios como un candidato ideal que fortaleciera su liderazgo. El autor destaca que los análisis de contenido de imágenes políticas "se han convertido en el análisis visual estándar de los marcos de medios" (p. 8) y que los marcos propuestos por Grabe y Bucy se han encontrado en medios online, luego de ser utilizados por las campañas políticas para comunicarse con los votantes.

\section{Humor y viralidad}

Las teorías que circundan al humor como un elemento de cambio social comprenden principalmente los estudios de Shifman (2007), quien señala que "el humor puede servir como una llave única para la comprensión de los procesos sociales y culturales" (p. 187). Shifman (2012) y Knobel y Lankshear (2007) comparten la noción de que el humor es una característica clave y un componente central de los memes en la red. Shifman (2011) encuentra que tres conceptos importantes en la definición de la teoría del humor memético también se hallan presentes en la mayoría de los memes. Estos conceptos incluyen el juego (invitar a los espectadores a participar en un juego), la incongruencia (un encuentro cognitivo inesperado entre dos elementos incongruentes) y la superioridad (el espectador se percibe como superior al otro).

Para complementar esta tipología, Malin (2005) explica que la masculinidad defectuosa es otra de las características humorística del fenómeno memético porque en las imágenes o videos jocosos persisten mayoritariamente la aparición de más hombres que mujeres. Este tipo de humor responde a la llamada "crisis de la masculinidad" en la sociedad occidental contemporánea al presentar memes que se burlan o veneran a hombres que no son perfectos y que no cumplen funciones básicas en su vida personal y profesional. Shifman (2011) encontró en su estudio que la mayoría de personajes con masculinidad defectuosa no cumplían con las expectativas masculinas actuales y generalmente pertenecían al mundo 
de la cultura popular y del comic.

Por su parte Freelon y Karpf (2015) destacaron que el humor incluye usualmente referencias a personajes de la cultura popular para comunicar mensajes claramente partidista con el objetivo principal de aumentar la viralidad del mensaje. De esta manera, los usuarios pueden adjuntar comentarios y opiniones que tienen sentido dentro del contexto popular del evento original. Sin embargo, señalaron que si bien el humor tiene un rol principal en la expresión de ideas políticas visuales y textuales, su estudio como comentario político en tiempo real todavía está en una etapa temprana de desarrollo. Dahlgren (2009) destaca las propiedades del meme como una nueva modalidad de pensamiento y expresión que le permite a las audiencias participar en el discurso público. Además, el meme adquiere relevancia como arma política que permite, a través de la utilización del humor y la sátira, relacionarse con el discurso público para lograr una mejor comprensión de los procesos sociales y culturales (Dahlgren, 2009). Heath y Heath (2007) desarrollaron una amplia teoría que explica por qué unas ideas (no necesariamente los memes) son más pegajosas o virales que otras. Para los autores, la fecundidad de una idea radica en el cumplimiento de cuatro imperativos que logran en el público tener el efecto deseado: Dichos atributos son la simplicidad (una idea breve que sintetiza una situación y que sea entendible para la gente), lo inesperado (imágenes sorpresivas que generan un cambio emocional y curiosidad en el público), lo concreto (ideas específicas) y la coherencia con el relato (una idea contada en forma de historia).

Después de esta extensa revisión teórica, este estudio formula las siguientes preguntas de investigación:

P1: ¿Qué características de los encuadres (visuales y textuales) hicieron que los memes políticos fueran distribuibles (virales) a través de las redes sociales en el contexto de la campaña presidencial colombiana de 2018?

P2: ¿Cuál es el encuadre de medios utilizado por los usuarios en sus memes para determinar el perfil de los candidatos (ideal, populista o perdedor seguro) en la campaña presidencial colombiana de 2018?

P3: ¿Cuáles son los atributos del meme como herramienta humorística y viral que le permitieron relacionarse con el discurso público a través de la red social Twitter durante la campaña presidencial colombiana de 2018?

P4: ¿Cuáles son las características que generaron mayores interacciones entre los usuarios, en torno a la disputa electoral de 2018? 


\section{Metodología}

Para la consecución de los objetivos de este estudio, se utilizó una metodología multimodal de análisis de contenidos. Tal como plantean Kress y Van Leeuwen (2001), la multimodalidad permite el uso de varios modos semióticos (la imagen, el video, los dibujos, las fotografías), además de la palabra escrita, que al ser combinados de una manera determinada permiten crear nuevos significados (Pastene \& Haquin, 2017).

Este estudio es de tipo transversal porque examinó las categoría de análisis en un periodo de tiempo determinado. La investigación recopiló solamente los memes generados durante los debates de la primera vuelta presidencial desarrollados entre el 1 de abril y el 27 de mayo de 2018. No se tuvo en cuenta la segunda vuelta presidencial debido a que únicamente tenía a los dos finalistas, Iván Duque y Gustavo Petro, lo que reducía el espectro político de los mensajes. Twitter fue la red social elegida para recoger la muestra porque es una de las principales herramientas en la que confluyen políticos, periodistas y usuarios para discutir la actividad política. Twitter les ha permitido a los usuarios debatir y compartir opiniones sobre política o sobre las noticias de última hora (Marchetti \& Ceccobelli, 2016). Marchetti y Ceccobelli han mostrado la estrecha relación que existe entre Twitter y otros medios de comunicación, especialmente con la televisión, que facilita la comunicación entre los usuarios conectados en red que ven los debates políticos en televisión. La relación entre Twitter y la televisión se aplica particularmente al entretenimiento y al debate político (Marchetti \& Ceccobelli 2016, p. 630).

En primera instancia, se eligieron los hashtags propuestos tanto por los medios de comunicación que televisaron los debates, como por la red social Twitter y por la Misión de Observación Electoral (MOE) en Colombia, durante los debates presidenciales ocurridos entre el 1 de abril y el 27 de mayo de 2018. La recolección de los memes se llevó a cabo en tiempo real. Los hashtags fueron elegidos porque los canales de televisión colombianos dominan el espectro de la discusión política durante los debates, lo que evidencia un estrecho vínculo entre lo que ocurre en los debates de televisión y la reacción que tienen las personas conectadas a las redes sociales (Giglietto \& Selva, 2014). Los memes fueron seleccionados de acuerdo con las nociones planteadas desde la teoría (incluyendo los GIFs y la caricatura), exceptuando los videos. Tampoco se tuvo en cuenta como unidad de análisis las respuestas que generaba el tweet. Seguidamente, se seleccionaron aquellos que estuvieran acompañados por el hashtag relacionado a un debate específico. La muestra final quedó conformada por diez hashtags y 358 memes.

Tabla 1. Hashtags seleccionados para el estudio 


\begin{tabular}{|l||l|}
\hline \multicolumn{1}{|c|}{ Hashtag } & Promotor del hashtag \\
\hline \hline \multirow{2}{*}{ \#ColombiaDecide } & $\begin{array}{l}\text { Misión de Observación Electoral (MOE) } \\
\text { y Twitter Latinoamérica }\end{array}$ \\
\hline \hline \#DebateEnAntioquia & Teleantioquia (medio de comunicación) \\
\hline \hline \#DebateEnCapital & Canal Capital (medio de comunicación) \\
\hline \hline \#Elecciones2018 & Twitter \\
\hline \hline \#ElDebate & El Tiempo (medio de comunicación) \\
\hline \hline \multirow{2}{*}{ \#DebateCaribe } & $\begin{array}{l}\text { Universidad del Norte/El Heraldo (medio } \\
\text { de comunicación) }\end{array}$ \\
\hline \hline \#DebatePacífico & Telepacífico (medio de comunicación) \\
\hline \hline \multirow{2}{*}{ \#EleccionesColombia } & $\begin{array}{l}\text { Misión de Observación Electoral (MOE) y } \\
\text { Twitter Latinoamérica }\end{array}$ \\
\hline \hline \#ElGranDebate & Noticias RCN (medio de comunicación) \\
\hline \hline \#DebateFinal & Noticias Caracol (medio de comunicación) \\
\hline
\end{tabular}

Para cumplir con los objetivos planteados en la investigación, se implementó una metodología multimodal, que incluyó un análisis manual de contenido siguiendo un libro de códigos y el uso del programa estadístico SPSS que permite el procesamiento y obtención de estadísticas descriptivas y asociativas de los datos, tablas cruzadas, gráficas, entre otras características (Field, 2013). El análisis de contenido permitió identificar los encuadres visuales y textuales compartidos en los memes a través de la red social Twitter.

El instrumento de codificación para el análisis de contenido fue sujeto a una prueba de validez, a través de un juicio de expertos que permitió mejorar las categorías de análisis y evitar ambigüedades. En seguida, se evaluó la confiabilidad del libro de códigos mediante una prueba de coincidencia entre codificadores (Krippendorf, 2018). Para el desarrollo de la misma, dos codificadores independientes analizaron las 16 variables en una submuestra de 
30 memes. El procedimiento tuvo que repetirse en dos ocasiones más hasta alcanzar confiabilidad en todas las variables. Para el análisis de los datos, se procedió a extraer mediante el programa estadístico SPSS las tendencias centrales de las categorías de análisis para establecer frecuencias, porcentajes y medias correspondientes. En la siguiente tabla se encuentran el Krippendorf Alpha de cada una de las categorías.

Tabla 2. Confiabilidad entre 2 codificadores 


\begin{tabular}{|c|c|}
\hline Variable & $\begin{array}{l}\text { Krippendorff's } \\
\text { Alpha }\end{array}$ \\
\hline $\begin{array}{l}\text { V1. Humor: La imagen se percibe como una 'píldora de bienestar', un estímulo cómico que pretende } \\
\text { provocar risa, o al menos, una sonrisa (Ballesteros Doncel, E. 2016). }\end{array}$ & 1 \\
\hline $\begin{array}{l}\text { V1a. Tipo de humor: El tipo de humor presente en la imagen: 1. juego 2. Incongruencia } 3 . \\
\text { superioridad 4. masculinidad defectuosa }\end{array}$ & 0.844 \\
\hline $\begin{array}{l}\text { V2. Repetición: La imagen presenta una idea simple repetitiva que genera recordación y, por ende, } \\
\text { permite la fácil recordación para el éxito del meme (Shifman, 2012). }\end{array}$ & 0.86 \\
\hline $\begin{array}{l}\text { V3. Contenido: Dentro del cuerpo del meme se evidenciaba un contenido 1. Cultura, 2. Política, } 3 . \\
\text { Religión, 4. Paz, 5. Corrupción, 6. Sexo, 7. Economía, 8. Educación, 9. Otro }\end{array}$ & 0.857 \\
\hline $\begin{array}{l}\text { V4. Tono del meme: Las imágenes analizadas retratan manifestaciones positivas, optimistas de apoyo, } \\
\text { algunas no emiten juicio de valor y otras hacen alusión a quejas, malestar o enojo (Ayala, 2013; García, } \\
\text { 2013). } 1 \text { Positivo, 2. Negativo, 3. Neutro. }\end{array}$ & 0.765 \\
\hline $\begin{array}{l}\text { V5. Fuente u origen del meme: Quiénes son los actores que están hablando de política en Twitter: } \\
\text { 1.Políticos, 2.Organizaciones, 3.Usuarios, 4.Periodistas, 5.Medios de comunicación }\end{array}$ & 1 \\
\hline $\begin{array}{l}\text { V6. Forma y manipulación visual: } 1 \text {. Guion, 2. Imagen, 3. Imagen compleja, 4. Caracteres } \\
\text { adicionales, 5. Collage, 6. Lista de imágenes, 7. Historia visual (estilo cómic) }\end{array}$ & 0.926 \\
\hline $\begin{array}{l}\text { V7. Viralidad/ Memes efectivos o pegajosos: cuál es la característica de pegajosidad del meme } \\
\text { presente en la imagen: } 1 \text {. Simples, } 2 \text {. Inesperado, 3. Concreto, } 4 \text {. Coherencia en el Relato }\end{array}$ & 0.771 \\
\hline $\begin{array}{l}\text { V8. Conflicto y Temática: } 1 \text {. Temática: El meme implica la selección de un atributo o temática } \\
\text { particular con el fin de hacerla más destacada en las mentes de los ciudadanos (Guber, D. L., \& Bosso, } \\
\text { C. J. 2012). 2. Conflicto: El meme refleja y ayuda a entender los desacuerdos que se libran en la } \\
\text { realidad y escenario político (Bartholomé, G., Lecheler, S., \& de Vreese, C. 2015). }\end{array}$ & 0.901 \\
\hline $\begin{array}{l}\text { V9. Diferencias entre grupos sociales: } 1 \text {. Ricos y Pobres } 2 \text {. Empresarios y trabajadores } 3 \text {. } \\
\text { Empleados y desempleados } 4 \text {. Hombres y Mujeres } 5 \text {. Gente joven y la sociedad } 6 \text {. Personas de distinta } \\
\text { raza } 7 \text {. Nacionales y extranjeros } 8 \text {. Adulto mayor y la sociedad } 9 \text {. Otro }\end{array}$ & 0.746 \\
\hline $\begin{array}{l}\text { V10. Problemáticas más importantes en Colombia: } 1 \text {. Delincuencia/Seguridad pública } 2 . \\
\text { Problemas económicos } 3 \text {. Problemas de la política 4. Problemas de la educación } 5 \text {. Problemas de la } \\
\text { salud 6. Violencia 7. Otros. }\end{array}$ & 0.841 \\
\hline $\begin{array}{l}\text { V11. Posición ideológica: El meme contiene una referencia explícita a cuestiones relacionadas con } \\
\text { una posición ideológica (clásica) de: } 1 \text {. Izquierda 2. Centro (independiente) 3. Derecha } 4 \text {. Ninguna }\end{array}$ & 0.794 \\
\hline $\begin{array}{l}\text { V12. Candidato en la imagen: } 1 \text {. Germán Vargas Lleras } 2 \text {. Iván Duque } 3 \text {. Gustavo Petro } 4 \text {. Sergio } \\
\text { Fajardo } 5 \text {. Humberto de la Calle } 6 \text {. Ningún candidato sale en la imagen. No hay referencia hacia ningún } \\
\text { candidato. } 7 \text {. Todos los candidatos salen en la imagen o se hace referencia a ellos en el texto. }\end{array}$ & 1 \\
\hline $\begin{array}{l}\text { V13. Pro-Anti Grupos de Memes: Si el meme parece tener alusiones positivas hacia el candidato, } \\
\text { codifíquelo dentro de la categoría 1. pro. La categoría 2. anti pertenece a los memes con una alusión } \\
\text { negativa o que intentan derrotar al aspirante. (Foster, B. 2014). }\end{array}$ & 1 \\
\hline $\begin{array}{l}\text { V14. Encuadre de medios del perfil de los candidatos tradicionales: } 1 \text {. Candidato ideal } 2 . \\
\text { Activista populista } 3 \text {. Perdedor seguro } 4 \text {. No sale el candidato en la imagen del meme. }\end{array}$ & 0.864 \\
\hline $\begin{array}{l}\text { V15. Intención política y comunicativa meme: } 1 \text {. Dar apoyo 2. Generar controversia 3. Dar una } \\
\text { respuesta } 4 \text {. Generar conversación } 5 \text {. Reforzar una actitud u opinión (ideologías políticas) }\end{array}$ & $0.81(85 \%)$ \\
\hline $\begin{array}{l}\text { V16. Tipo de meme: } 1 \text {. Memes Genéricos (El meme extrae referencias de una cultura popular a partir } \\
\text { de referencias de la televisión, música, películas, videojuegos, o libros (Knobel \& Lanksear, 2006). } \\
\text { 2.Memes originales: Memes que aparecen espontáneamente en campaña o son generados } \\
\text { principalmente por el usuario de manera independiente y no utilizan aspectos de la cultura popular } \\
\text { para la creación de la imagen. }\end{array}$ & 0.768 \\
\hline
\end{tabular}




\section{Procedimientos estadísticos de los datos}

Para responder a las primeras preguntas, se corroboró si existía una asociación estadísticamente significativa entre las principales categorías de análisis (tipos de humor, viralidad y encuadre de medios del perfil de los candidatos tradicionales) mediante tablas cruzadas, reportando el Chi-Cuadrado $\left(\mathrm{X}^{2}\right)$ y la significación de esos cruces asociativos. Con el objetivo de estudiar la viralidad y características de los memes, se realizó un análisis de contenido multimedia (tanto del texto como la imagen), en el que se aplicó un test estadístico que mide el número de interacciones (retweets) para verificar si las características de los memes aumentan o no el número de esas interacciones. A su vez, para determinar variaciones, similitudes, diferencias o comparaciones entre las medias de diversos grupos se realizó el análisis de varianza ANOVA que permitió evidenciar el efecto de una variable sobre otra (Robles, s.f.). Para buscar diferencias más específicas entre las categorías de análisis se realizó, también, la prueba HSD de Tukey, un test post-hoc que analiza comparaciones múltiples para conocer la relación interna entre las medias de un grupo con otro (Abdi \& Williams 2010).

\section{Resultados y Análisis}

En la investigación se confirma la noción del meme como uno de los instrumentos de denuncia contra la corrupción en la esfera política nacional durante un proceso electoral. Lo ratifica como una voz de resistencia gracias al uso de características propias del humor y la viralidad que le permiten a la ciudadanía apoyar o atacar a un determinado aspirante con base a las características propias del encuadre de medios del perfil de los candidatos.

El encuadre del candidato ideal fue usado por la mayoría de los usuarios para enmarcar a Gustavo Petro, quien tuvo el apoyo mayoritario de la muestra por parte de las audiencias digitales, mientras que Iván Duque, no solo resultó el aspirante más relacionado con el encuadre del candidato perdedor, sino que también fue el más asociado por las audiencias digitales con contenidos de corrupción. De nuevo, vemos que no hay necesariamente una correspondencia entre el debate político en red utilizando el meme como instrumento y lo que ocurre en la participación política real, en la que Duque resultó electo en segunda vuelta.

Los usuarios, quienes son los generadores y consumidores de memes, recurrieron a la creatividad como forma de expresión - similar al grafiti- para ofrecer nuevas formas de manipulación visual, tales como el guion, y para promover sus ideales políticos. De esta manera, no solo evitaron el uso repetitivo de memes genéricos, sino que basaron sus críticas en memes que parecían tener la estrategia intencional de evadir y hacer frente a la censura. Del total de la muestra, 99 memes reaccionaron al hashtag \#DebateEnAntioquia, la etiqueta más utilizada en el estudio por los usuarios digitales.

Respecto a los contenidos de la muestra, aquellos relacionados con la política (68,4\% 
$\mathrm{N}=245)$ y la corrupción (20,7\% N=74) tienen mayor prelación e interés para los usuarios digitales que los temas de economía $(3,4 \% \mathrm{~N}=12)$ o educación $(1,4 \% \mathrm{~N}=5)$ en el contexto de las elecciones en Colombia. En cuanto a los actores o fuentes que generan memes políticos dentro de los espacios de debate en la red social Twitter, se encontró que fueron los usuarios digitales quienes realizaron una mayor propuesta de memes con una frecuencia más alta $(80,2 \% \mathrm{~N}=287)$ que los medios de comunicación $(1,4 \% \mathrm{~N}=5)$. Por su parte, los usuarios de Twitter se inclinan más por compartir aquellos memes que generan conversación $(42,5 \% \mathrm{~N}=152)$ y controversia $(22,3 \% \mathrm{~N}=80)$ que por transferir aquellas imágenes que podían reforzar actitudes y opiniones $(8,7 \% \mathrm{~N}=31)$ o generar apoyo $(14,8 \%$ $\mathrm{N}=53)$.

El tipo de meme más usado por los usuarios digitales para entablar conversaciones en los debates presidenciales de 2018 fue el meme original (72,3\% N=259), -es decir, aquellos generados por los usuarios de manera independiente y que no utilizan aspectos de la cultura popular como referencia para la creación de la imagen-, mientras que el meme genérico -que hace referencia a algún hecho en particular de contingencia nacional o internacional mediante imágenes populares en la red-, tuvo una frecuencia menor $(27,7 \% \mathrm{~N}=99)$. Esto significa que los usuarios digitales apelan a la creatividad al momento de replicar sus mensajes, son más críticos con su intención y evitan replicar memes referentes a la cultura popular.

En cuanto a los candidatos en la imagen, el candidato Iván Duque, $(34,1 \% \mathrm{~N}=122)$ fue el que más apareció representado en la muestra total, seguido por Gustavo Petro, $(28,2 \%$ $\mathrm{N}=101)$. Los otros candidatos presidenciales también fueron relacionados en la muestra total de memes, pero con menor frecuencia: Germán Vargas Lleras, $(8,4 \% \mathrm{~N}=30)$, (Sergio Fajardo, $(9,8 \% \mathrm{~N}=35)$, y Humberto de La Calle, $(7,0 \% \mathrm{~N}=25)$.

\section{Encuadre de medios del perfil de los candidatos}

Los resultados demuestran que, del total de imágenes, $(\mathrm{N}=358)$, los memes que enmarcan a los candidatos como perdedores seguros obtuvieron una mayor frecuencia $(46,4 \%$ $\mathrm{N}=166)$, que otras categorías de variables como el candidato ideal $(34,9 \% \mathrm{~N}=125)$ y el activista populista $(7,8 \% \mathrm{~N}=28)$, (véase gráfico No. 1). Esto significa que el descontento de los usuarios digitales está plasmado en los encuadres que presentan a los candidatos como aspirantes fallidos, además de presentarlos en memes que reflejan poses visuales no apropiadas que generan burla.

Gráfico No. 1 Encuadre de medios del perfil de los candidatos 


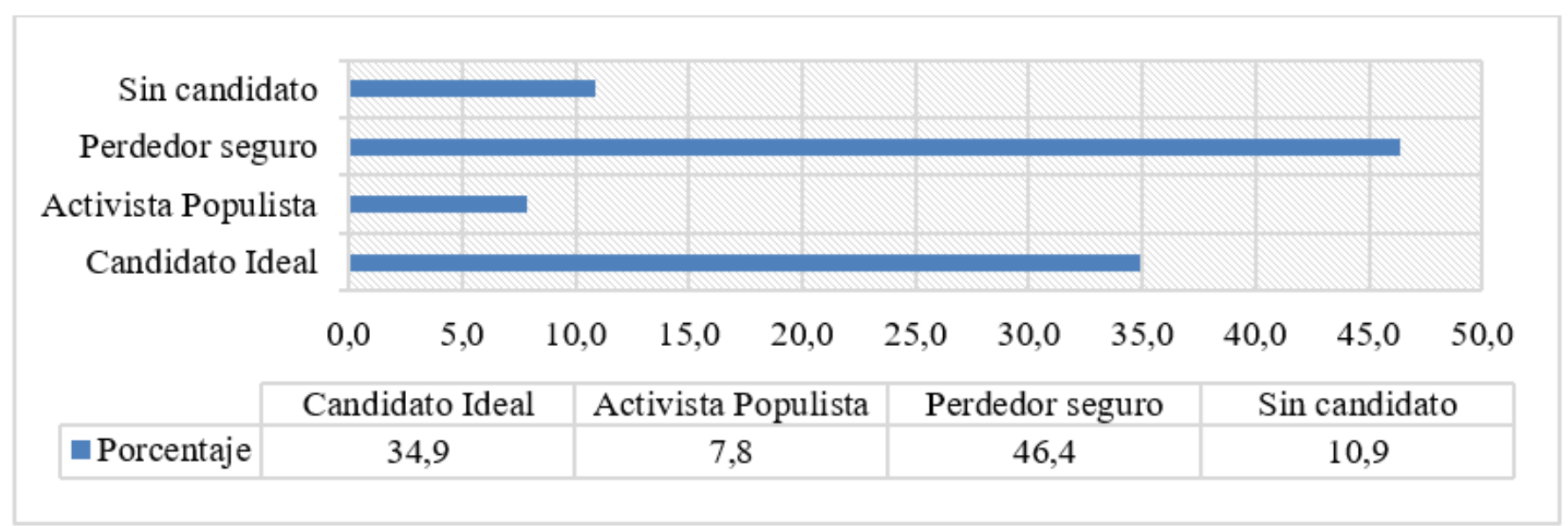

Adicional a ello, la asociación entre el encuadre de medios del perfil de los candidatos y el tipo de humor reveló que el candidato perdedor seguro $(55,4 \% \mathrm{~N}=92)$ es el que genera mayor humor de juego $\left(\mathrm{X}^{2}=90,088 \mathrm{df}=9 \mathrm{p}<0.00\right)$, en comparación del activista populista $(9,6 \% \mathrm{~N}=16)$ y el candidato ideal $(21,1 \% \mathrm{~N}=35)$. Esto significa que los contenidos relacionados con el perdedor seguro, muchas veces asociado a Iván Duque, utilizaban imágenes para compartir, generar, replicar o dar un nuevo sentido a memes que explicaban de manera creativa y graciosa situaciones sociales en Twitter. Mientras tanto, el candidato ideal resultó más frecuentemente asociado al humor de superioridad $(88.9 \% \mathrm{~N}=48)$. Esto significa que la mayoría de los memes relacionados con el candidato ideal, en su mayoría atribuidos a Gustavo Petro, lo presentan en Twitter como un candidato superior que exaltaba contantemente las debilidades de los demás. (Véase Tabla No. 3).

Tabla 3: Encuadre de medios del perfil de los candidatos y tipo de humor 
Tipo de humor

\begin{tabular}{|c|c|c|c|c|c|}
\hline $\begin{array}{l}\text { Encuadre de } \\
\text { medios del } \\
\text { perfil de los } \\
\text { candidatos }\end{array}$ & $\begin{array}{l}\text { Juego } \\
(\%, n)\end{array}$ & $\begin{array}{l}\text { Incongruenc } \\
\text { ia }(\%, n)\end{array}$ & $\begin{array}{l}\text { Superiorida } \\
d(\%, n)\end{array}$ & $\begin{array}{l}\text { Masculinida } \\
\text { d defectuosa } \\
(\%, n)\end{array}$ & $\begin{array}{l}\text { Total } \\
(\%, n)\end{array}$ \\
\hline $\begin{array}{l}\text { Candidato } \\
\text { ideal }\end{array}$ & $\begin{array}{l}21.1 \\
(35)\end{array}$ & $37.5(30)$ & 88.9 (48) & 26.9 (7) & $\begin{array}{l}36.8 \\
(120)\end{array}$ \\
\hline $\begin{array}{l}\text { Activista } \\
\text { populista }\end{array}$ & $\begin{array}{l}9.6 \\
(16)\end{array}$ & $3.8(3)$ & $3.7(2)$ & $3.8(1)$ & $\begin{array}{l}6.7 \\
(22)\end{array}$ \\
\hline $\begin{array}{l}\text { Perdedor } \\
\text { seguro }\end{array}$ & $\begin{array}{l}55.4 \\
(92)\end{array}$ & 48.8 (39) & $7.4(4)$ & $69.2(18)$ & $\begin{array}{l}46.9 \\
(153)\end{array}$ \\
\hline $\begin{array}{l}\text { Sin } \\
\text { candidato }\end{array}$ & $\begin{array}{l}13.9 \\
(23)\end{array}$ & 10. (8) & $0.0(0)$ & $0.0(0)$ & $\begin{array}{l}9.5 \\
(31)\end{array}$ \\
\hline Total $(\%, \mathrm{n})$ & $\begin{array}{l}100 \\
(166)\end{array}$ & $100(80)$ & $100(54)$ & $100(26)$ & $\begin{array}{l}100 \\
(326)\end{array}$ \\
\hline
\end{tabular}

$\left(X^{2}=90,088 d f=9 \quad p<0.00\right)$

\section{Características del meme}

Los hallazgos permiten evidenciar que la imagen, entendida como un meme compuesto por una representación visual fija y no móvil, fue usada en la mayoría de la muestra total (35,5\% $\mathrm{N}=127)$, junto con el guion $(22,1 \% \mathrm{~N}=79)$ y la imagen compleja $(19,3 \% \mathrm{~N}=69)$. El recurso menos utilizado por los usuarios fueron los caracteres adicionales $(2,0 \% \mathrm{~N}=7)$ y el collage $(3,1 \% \mathrm{~N}=11)$, (véase gráfico No. 2).

La riqueza y creatividad de los usuarios digitales en Twitter permite destacar que, además de las imágenes, los memes textuales o frases humorísticas acompañadas de imagen empiezan a cobrar más relevancia en el escenario digital. Sin embargo, la imagen fija continúa siendo el recurso visual más empleado por los usuarios porque parece generar más recordación entre las audiencias debido a los comentarios creativos, irónicos y graciosos que acompañan el cuerpo del tweet.

Gráfico No. 2 Características de contenido y forma del meme 


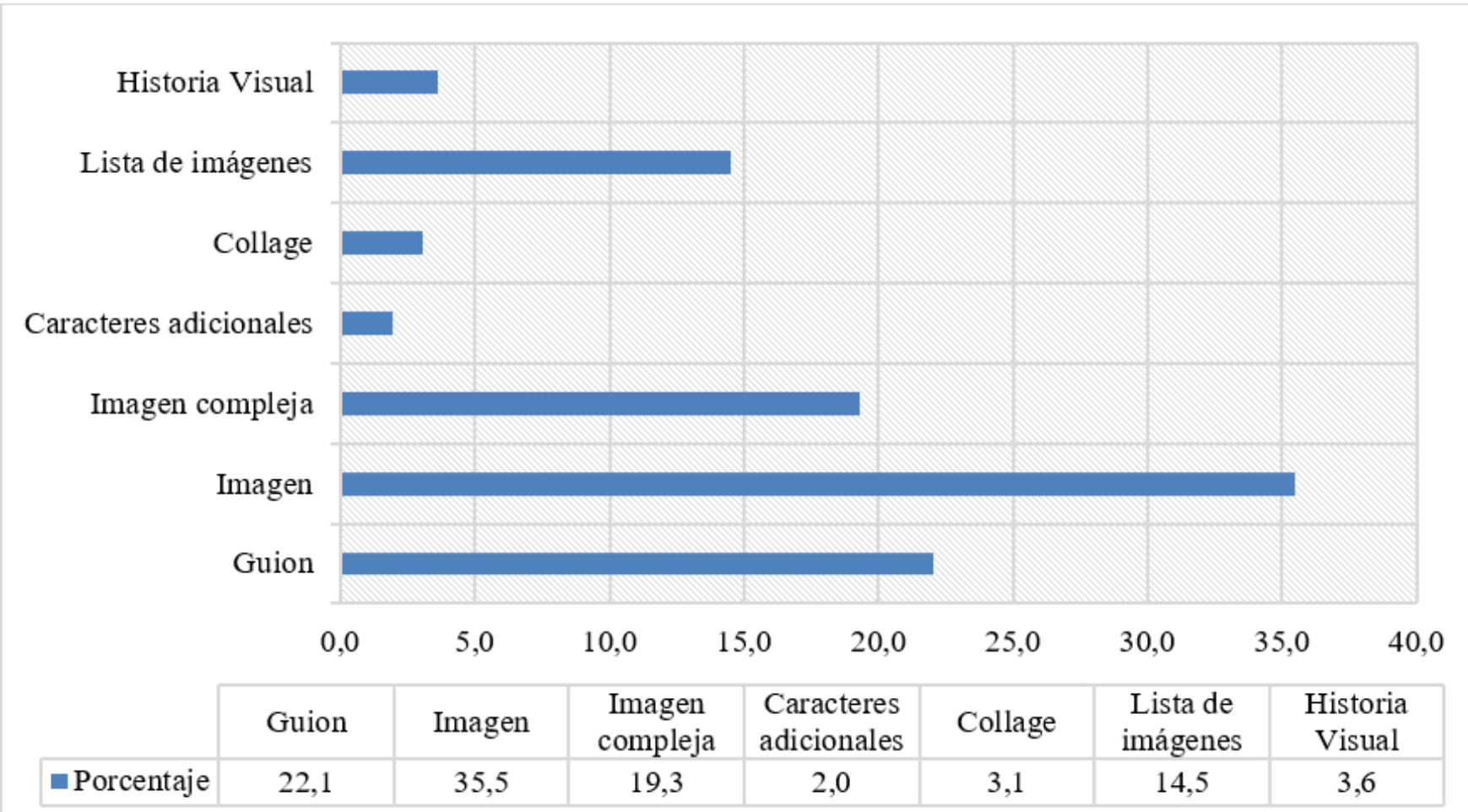

\section{Propiedades humorísticas y virales del meme}

El tipo de humor más utilizado por los usuarios fue el juego $(46,4 \% \mathrm{~N}=166)$, seguido por la incongruencia $(22,3 \% \mathrm{~N}=80)$, la superioridad $(15,1 \% \mathrm{~N}=24)$ y la masculinidad defectuosa $(7,3 \% \mathrm{~N}=26)$. En efecto, los usuarios digitales utilizan el juego, usualmente, para promover historias narrativas sobre la política nacional, mientras la incongruencia, la superioridad o la masculinidad defectuosa pueden emplearse para referirse, en específico, a un candidato o protagonista de la política nacional, (véase gráfico No. 3).

Gráfica No. 3 Tipo de humor encontrado en el meme

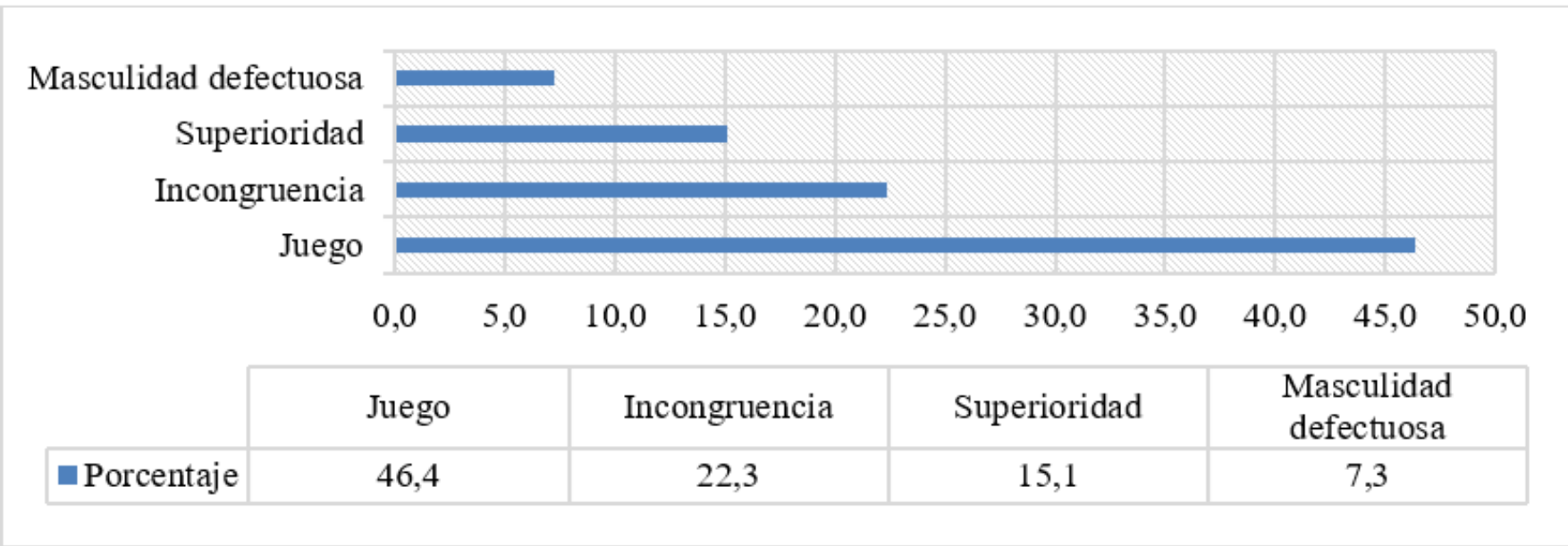

A su vez, al analizar la relación entre el tipo de humor y el candidato en la imagen reveló 
que el juego (69,9\% N=79) es el tipo de humor que más se asocia a la imagen de Iván Duque $\left(\mathrm{X}^{2}=146,767 \mathrm{df}=9 \mathrm{P}<0.00\right)$, por encima de otras categorías de análisis como la incongruencia $(20,4 \% \mathrm{~N}=23)$ y la superioridad $(3,5 \% \mathrm{~N}=4)$. La superioridad $(46,1 \% \mathrm{~N}=41)$, por el contrario, fue el tipo de humor que los usuarios más utilizaron para representar a Gustavo Petro, mientras que la incongruencia $(68,0 \% \mathrm{~N}=17)$ fue el recurso humorístico más utilizado para promover relacionados con Humberto de La Calle $\left(\mathrm{X}^{2}=146,767 \mathrm{df}=9 \mathrm{P}<\right.$ 0.00). A su vez, la masculinidad defectuosa $(31,0 \% \mathrm{~N}=9)$ fue la modalidad humorística que más fomentó memes vinculados con Germán Vargas Lleras. Esto significa que en los debates presidenciales hubo perfiles claros que revelaban las características políticas de los candidatos en la red: Petro como el aparente "ganador" que se sentía superior a sus adversarios, Vargas Lleras como representante de la "crisis de la masculinidad" en la campaña, De la Calle, como el candidato que más manipulaciones gráficas tuvo en la muestra, y Duque como el aspirante que más fue objeto de burla y creatividad por parte de las audiencias.

Los resultados de un análisis descriptivo revelan que, del total de la muestra, los contenidos relacionados con la viralidad simple $(62,6 \% \mathrm{~N}=224)$ y la inesperada $(18,7 \% \mathrm{~N}=67)$ tienen mayor uso por parte de los usuarios digitales respecto a otras categorías como la viralidad concreta $(2,2 \% \mathrm{~N}=8)$ o la coherente en el relato $(16,5 \% \mathrm{~N}=59)$, las cuales presentan una frecuencia menor. Así, la mayoría de los usuarios apela a memes que explican realidades complejas de manera sencilla y graciosa. (Véase gráfico No. 4).

Gráfico No. 4 Tipos de viralidad encontrada en el meme

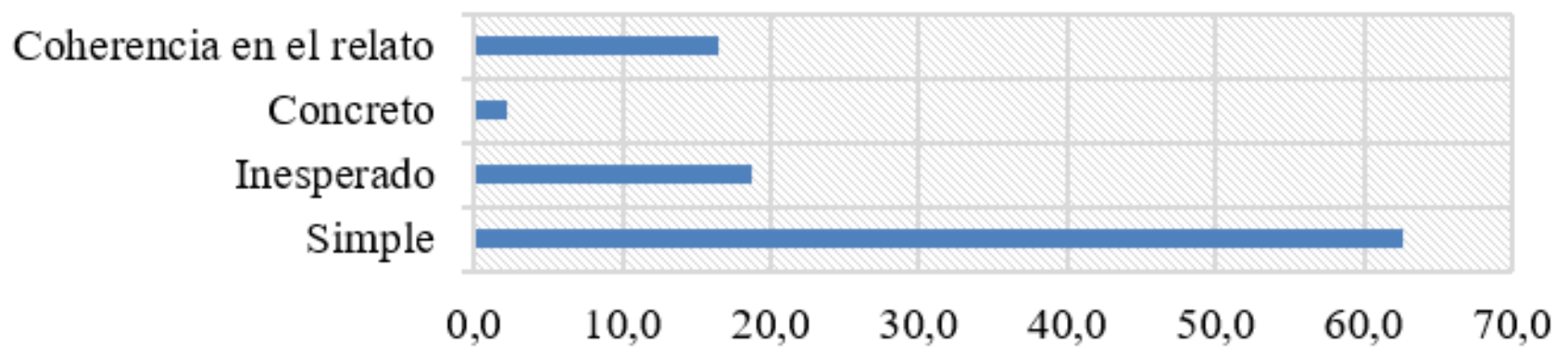

\begin{tabular}{|c|c|c|c|c|}
\hline & Simple & Inesperado & Concreto & $\begin{array}{c}\text { Coherencia en } \\
\text { el relato }\end{array}$ \\
\hline Porcentaje & 62,6 & 18,7 & 2,2 & 16,5 \\
\hline
\end{tabular}

Este estudio utilizó el encuadre de medios del perfil de los candidatos que Grabe y Bucy (2009) usaron para evaluar la manera en que se transmitían las noticias electorales y la forma en que los candidatos son percibidos por las audiencias. Grabe y Bucy (2009) señalaron que los encuadres que los usuarios perciben al momento de identificar a un 
aspirante se pueden calificar en el candidato ideal, el activista populista y el perdedor seguro.

Tras un análisis individual de cada uno de los aspirantes a la presidencia, el perdedor seguro apareció en 166 memes (46,4\%), el candidato ideal, en 125 memes $(34,9 \%)$ y el activista populista en 28 (7,8\%). Estos resultados respaldan las acepciones de Grabe y Bucy (2009) al destacar que el encuadre del perdedor seguro suele surgir por los ataques de la oposición, cuyo objetivo es controvertir la credibilidad, la honestidad y la confiabilidad de un candidato (p. 86). Si Iván Duque fue el aspirante político que más generó conversación y controversia en Twitter, tal incremento puede ser producto de la inconformidad y oposición que las audiencias digitales plasmaron durante los debates presidenciales. Por su parte la asociación de Gustavo Petro al encuadre del candidato ideal soporta las características que Grabe y Bucy (2009) señalan como las más atractivas de un aspirante en red.

En la imagen No. 1, a pesar de que la representación es una imagen abstracta, el texto del tweet evidencia la valoración que tienen los usuarios por candidatos sinceros y honestos que denuncian públicamente casos de corrupción en la esfera política colombiana. Esta dinámica le permitió a un gran grupo de usuarios relacionar o referenciar a Gustavo Petro como un candidato ideal en el contexto de un debate electoral y enmarcar a su principal contendor, Iván Duque, como el candidato perdedor seguro. 


\section{Celso Tete Crespo}

Belsemblante

\section{Seguir}

Le dice @petrogustavo a @IvanDuque:

"Yo renuncié al POLO y denuncié la

corrupción de Samuel Moreno.

¿Renunciaría usted al partido que

fomentó los falsos positivos?". \#DebateCaribe.

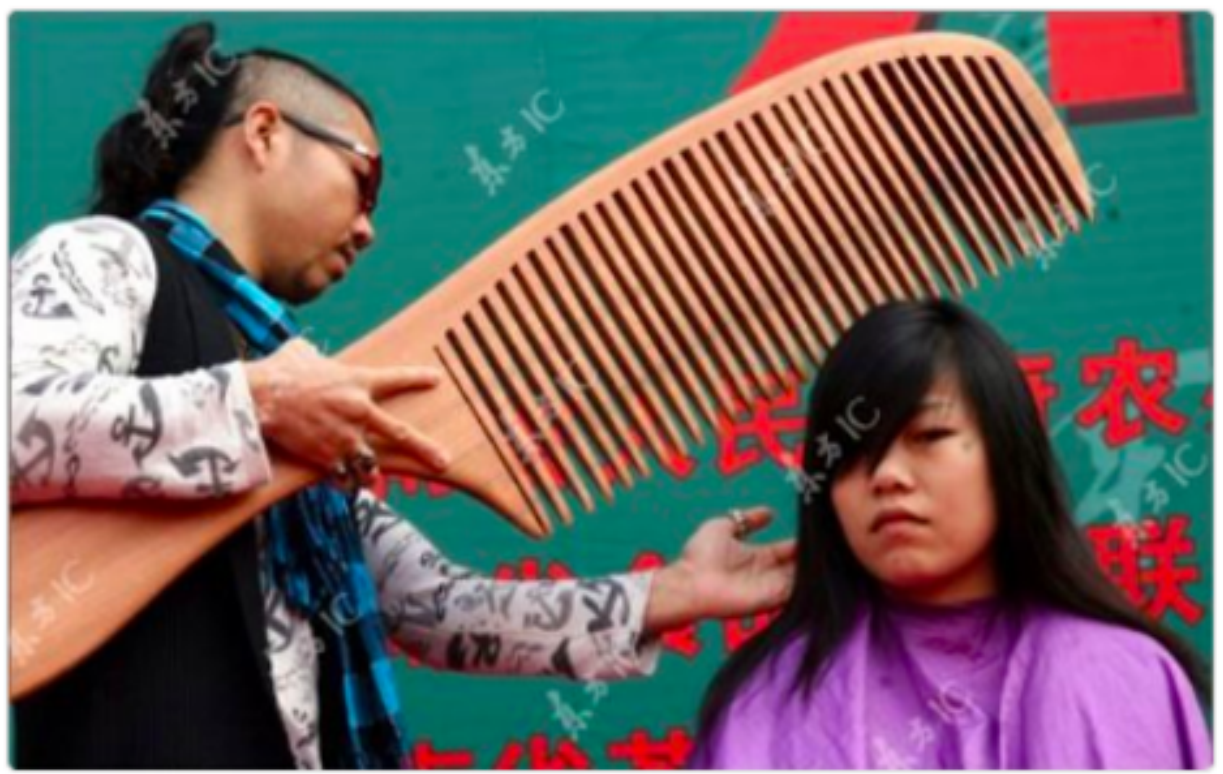

8:26 - 5 abr. 2018

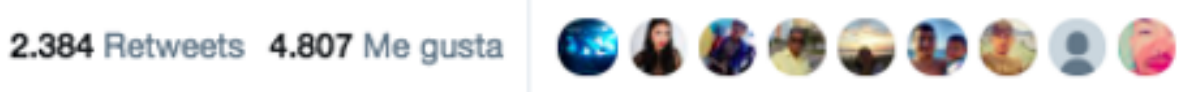

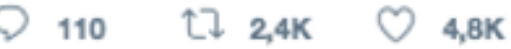

Imagen No. 1. Crespo, C. [elsemblante]. (5 de abril de 2018). Le dice @petrogustavo a @IvanDuque: "Yo renuncié al POLO y denuncié la corrupción de Samuel Moreno.

¿Renunciaría usted al partido que fomentó los falsos positivos?". \#DebateCaribe [Trino]. Recuperado de https://twitter.com/elsemblante/status/981915917809577990

En la muestra, los usuarios utilizaron la superioridad como el tipo de humor más recurrente para representar a Gustavo Petro, quien junto a Humberto de la Calle fueron enmarcados como candidatos ideales en la muestra analizada. Los resultados apoyan las nociones 
ofrecidas por los distintos autores analizados en este estudio sobre la manera en la que los usuarios realizan adiciones gráficas a la fotografía mediante todo tipo de manipulaciones visuales (Shifman, 2012; Segev, E., Nissenbaum, A., Stolero, N., \& Shifman, 2015; Foster, 2014). De los 358 memes analizados, 127 fueron enmarcados en la categoría imagen $(35,5)$, 79 de ellos pertenecieron a la tipología del guion (22,1\%), 69 a imagen compleja (19,3\%), 52 a lista de imágenes (14,5\%), 11 a collage $(3,1 \%)$ y 7 caracteres adicionales $(2,0 \%)$.

El uso de estas formas de manipulación visual está acorde con el punto de vista de Freelon y Karpf (2015), quienes indican que la modificación de las imágenes, la edición o los gráficos animados (GIF) permiten no solo desarrollar nuevas narrativas, sino que funcionan como piezas fundamentales para la crítica en la esfera política. Sin embargo, resulta paradójico que, de las características analizadas, la más viral y replicada en Twitter sea un meme perteneciente a la categoría de caracteres adicionales $[F(2,740)=180618,328, p<0,001]$ que obtuvo la media más alta de retweets de la muestra $(\mathrm{M}=467,00)$ sobre las otras categorías, (véase imagen No. 2). Independiente de que los usuarios utilicen mayoritariamente imágenes sin editar para replicar sus contenidos, y con el objetivo de lograr un alto número de retweets, parece que resultaba más eficiente agregar personas o caracteres a la imagen con el fin de provocar, no solo más conversación, sino controversia. 'Uribe en Antioquia' presenta la adición de un personaje a la fotografía que hace alusión a la presencia del expresidente Álvaro Uribe durante una de las intervenciones de Iván Duque en el debate para insinuar que el candidato era solo un títere del ex mandatario. (Véase imagen No. 2). 


\section{JAJAJAJJA JAJAJAJA JAJAJAJA}

\section{JAJAJAJAJAJAJAJAJAJJAJAJA}

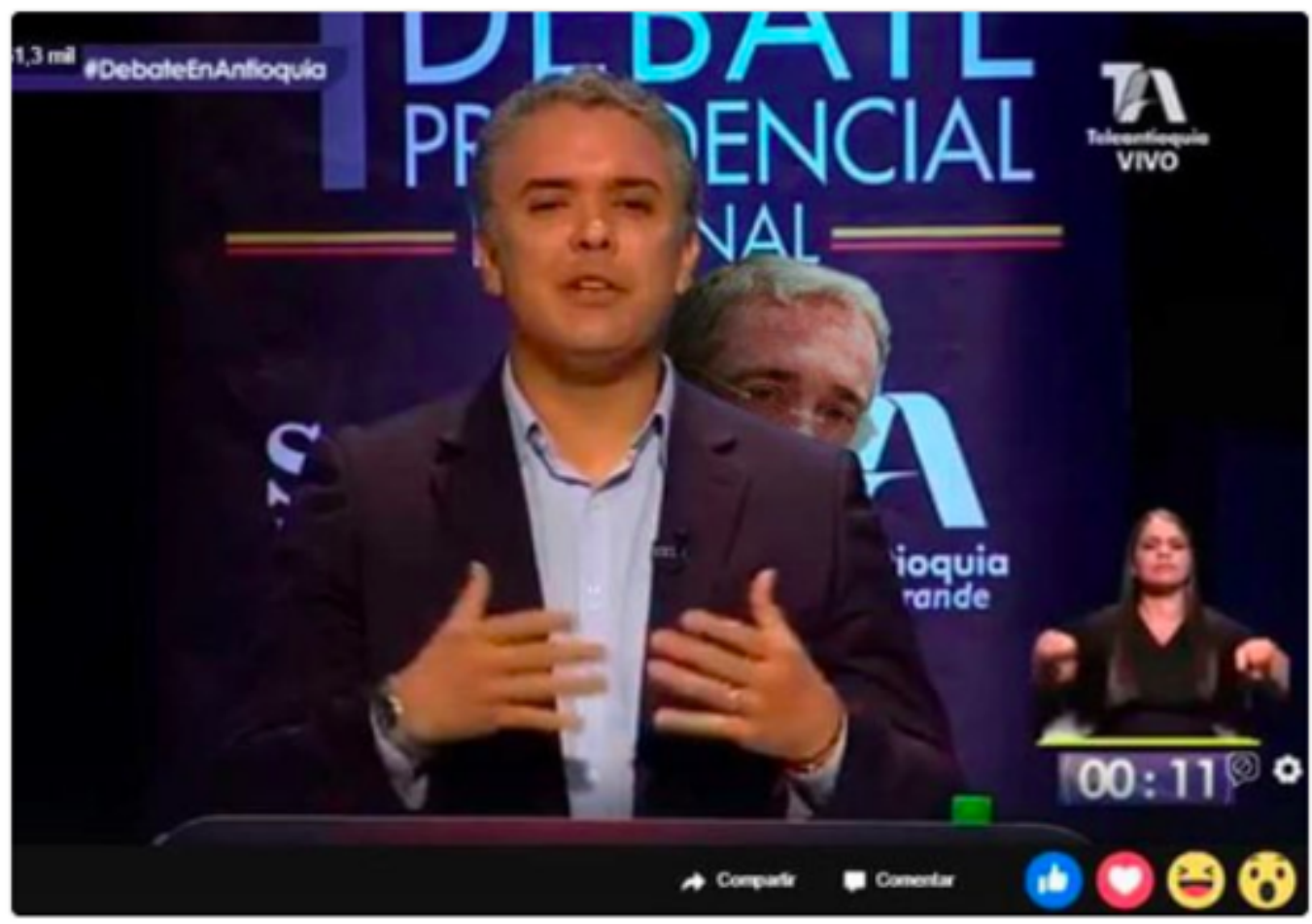

19:56 - 3 abr. 2018

\subsection{Retweets 2.422 Me gusta $408 \% 808$}

Q 52 โป $1,3 \mathrm{~K} \quad \mathrm{O}_{2,4 \mathrm{~K}} \quad \square$

Imagen No.2. @SiganAlPastuso. (3 de abril de 2018). JAJAJA \#DebateAntioquia JAJAJA [Trino]. Recuperado de https://twitter.com/SiganAlPastuso/status/981364751811915788

Las principales características del humor encontradas fueron, jerárquicamente, el juego $(46,4 \% \mathrm{~N}=166)$, la incongruencia $(22,3 \% \mathrm{~N}=80)$, la superioridad $(15,1 \% \mathrm{~N}=24)$ y la masculinidad defectuosa $(7,3 \% \mathrm{~N}=26)$. Dichos atributos conforman la definición de la teoría memética propuesta por Shifman (2012) y Malin (2005), quienes aseveran que estos componentes son ejes centrales de los memes en línea. Efectivamente, las audiencias digitales que utilizaron la superioridad como el tipo de humor para apoyar a un candidato lo hicieron con memes que también buscaban polarizar el debate público. El humor, en cada caso, tiene la intención de aumentar la propagación o "viralidad" del mensaje (Jenkins et al., 
2013), de la misma manera que lo hacen los programas de comedia política. Los resultados también son consistentes con la noción compartida por Freelon y Karpf (2015) en cuanto a que el humor ha sido observado como un terreno común que los periodistas y los usuarios interesados en la política comparten en Twitter (p. 372).

Ahora, siguiendo los aportes que Adegoju y Oyebode (2015), el humor fue la herramienta más utilizada en el estudio para desacreditar a un objetivo, pues el uso del sarcasmo contra el contendor parece ser utilizado para aumentar el valor electoral del candidato preferido y de su partido político. En la imagen No. 3 el usuario recurre al juego para presentar a Iván Duque como un cerdo que tiene miedo de ser llevado "al matadero" para enfrentarse una vez más en un debate con Gustavo Petro. Asimismo, el uso de memes originales que utilizan el juego como forma de humor más efectivo para desacreditar un rival político confirma el punto de vista de Dahlgren (2009), quien sostiene que la capacidad de involucrarse con "nuevas modalidades de pensamiento y expresión" y reapropiarlas de manera imprevista, significa la capacidad de participar más plenamente en el discurso público (p. 110). 


\section{Memín}

(3) SenorCaicedo

\section{Seguir}

\section{¿Adivinen quien no quiere ir al \#DebatePacifico por miedo a que @petrogustavo lo peine?}

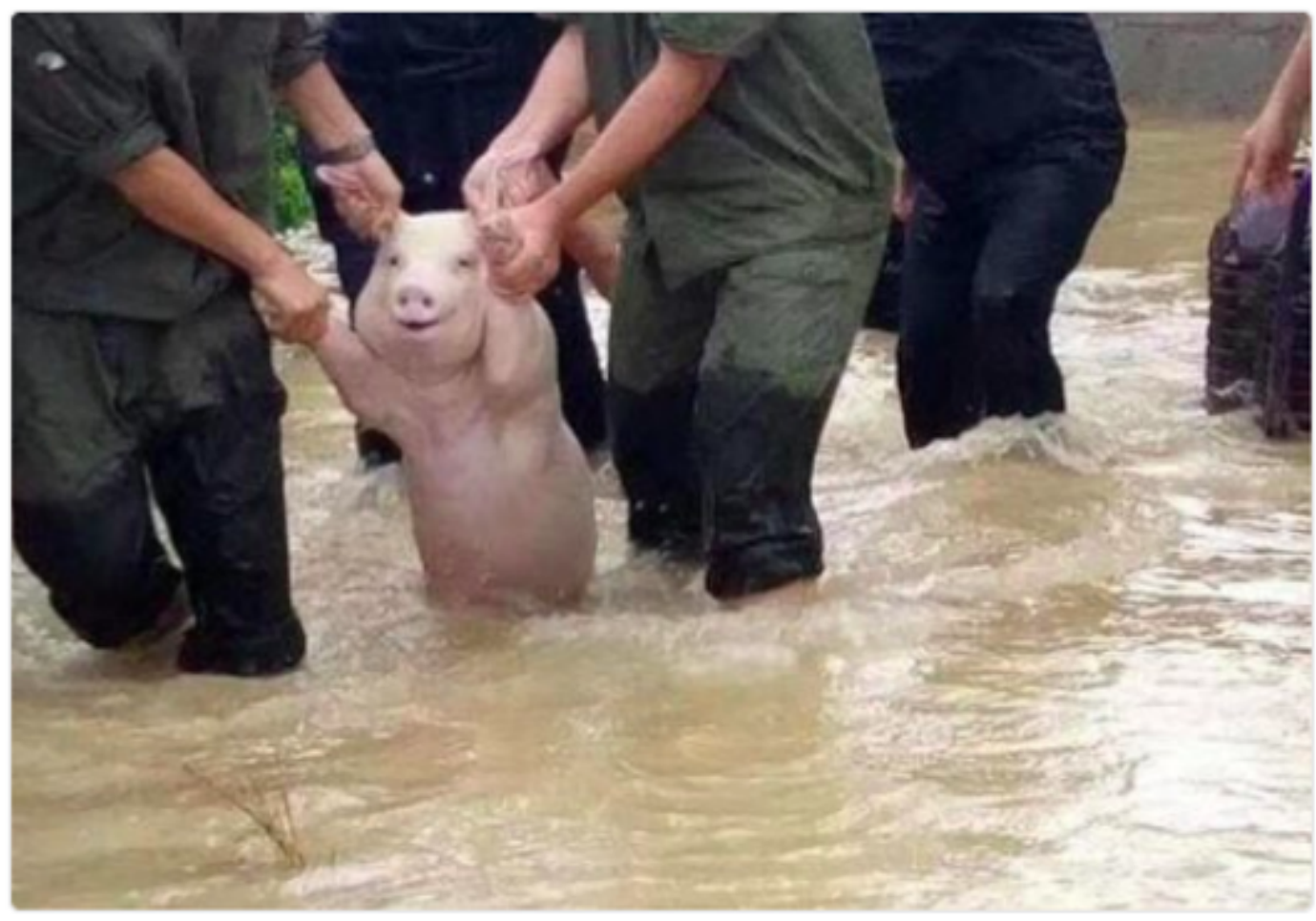

15:06 - 10 abr. 2018

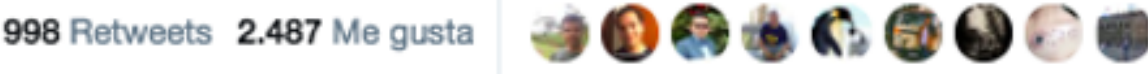

\section{$101 \quad$ โ] $998 \quad \bigcirc_{2}, 5 \mathrm{~K} \quad \square$}

Imagen No. 3. @SenorCaicedo. (9 de mayo de 2018). ¿Adivinen quien no quiere ir al \#DebatePacifico por miedo a que @petrogustavo lo peine? [Trino]. Recuperado de https://twitter.com/SenorCaicedo/status/983828635479166976

La investigación reveló que la viralidad más utilizada para replicar un meme es la viralidad simple y sus asociaciones con el candidato en la imagen. Dichos atributos son consistentes con la propuesta que Heath y Heath (2007) realizan para describir cómo una idea puede ser más pegajosa que otra en la red. Sin embargo, uno de los resultados inesperados encontrados fue que, si bien la viralidad simple es la más utilizada por los usuarios digitales, es la viralidad concreta $[F(4,014)=265635,692, p<0,001]$ la que obtuvo la media más alta de retweets de la muestra $(\mathrm{M}=441,38)$ sobre otras categorías. Esta efectividad en Twitter, 
no solo logra retweets, sino populariza contenidos altamente críticos sobre política y corrupción, (véase imagen no. 1). En este caso, en el meme priman las cosas concretas sobre los sustantivos abstractos, es decir el peine gigante representa la contundencia (la peinada, se dice en Colombia) de los argumentos de Gustavo Petro frente a Duque, cuando el exalcalde de Bogotá le recriminó al aspirante del Centro Democrático su vinculación con el partido que fomentó los falsos positivos en Colombia.

Por otro lado, los resultados respaldan los hallazgos obtenidos por Du Preez y Lombard (2014), quienes enfatizan que los sitios de redes sociales como Facebook o Twitter han modificado la manera en la que los memes se propagan. Para los autores, dichas redes son el ambiente más fértil para la exitosa transmisión de una imagen; es decir, el potencial o la fuerza para ser transmitido asegura también su persistencia en el tiempo. El presente estudio muestra que los memes evolucionaron a través de comentarios, imitaciones o parodias, o incluso a través de noticias relacionadas en otros medios. Por ejemplo, en la imagen No. 4, el meme hace referencia a la campaña de marca Nosotras con la que se buscaba empoderar a la mujer colombiana mediante el uso de la frase "No necesito tu aprobación". 


\section{Este meme ha sido el mejor del \#DebateFinal}

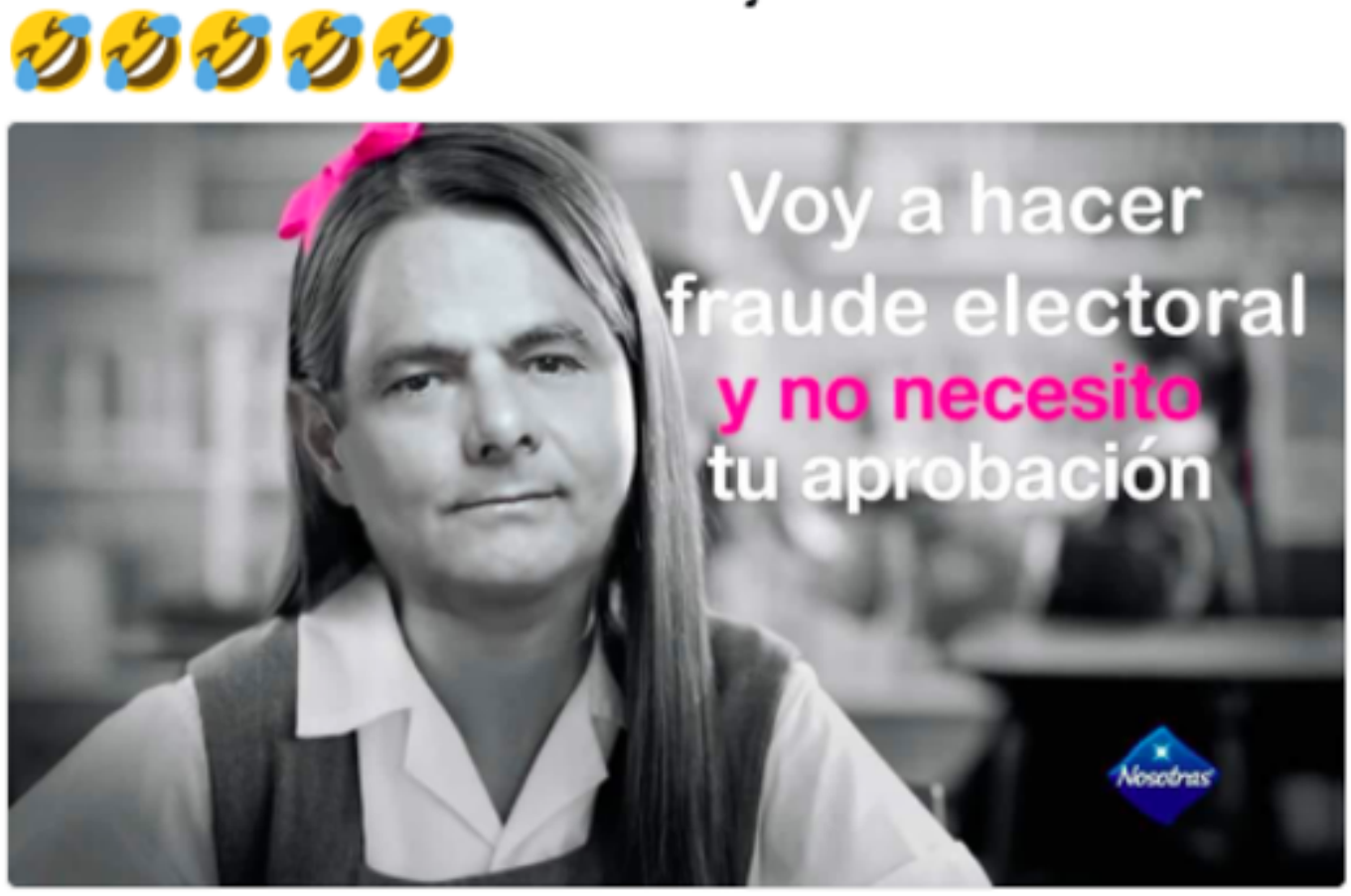

20:35 - 25 may. 2018 desde Colombia

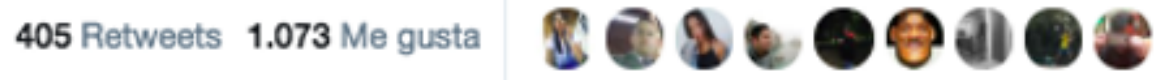

2 Oscar Montes, Jairo Soto Hernández, Marcela García Caballero y 6 más

Q 13 โป $405 \quad \bigcirc \quad 1,1 \mathrm{~K}$

\section{Conclusiones}

Los encuadres políticos que tienen características humorísticas como el juego suelen ser más efectivos en Twitter porque viralizan, no solo memes sobre un candidato perdedor, sino porque promueven contenidos que los asocian a fenómenos de corrupción en la esfera política colombiana. Los datos incluidos en este estudio pueden ser un aporte al entendimiento de cómo funciona la cultura y la transmisión de un meme en el contexto político electoral de los candidatos en las redes sociales y de cómo los usuarios encuadran el perfil de los aspirantes, en tiempo real, de acuerdo con su desempeño en debates electorales transmitidos por televisión (Grabe \& Bucy 2009).

También es importante resaltar que hay una tendencia en las redes sociales a deslegitimar al opositor en lugar de presentar las fortalezas del candidato propio o discutir diferencias 
entre las ideas políticas durante los debates electorales transmitidos en vivo. Este resultado del análisis de memes en el contexto colombiano se alinea con preocupaciones expresadas por otros académicos sobre la discusión política en la red; principalmente con el hecho de que se incentiven mensajes de ataque, odio y polarización, que no necesariamente contribuye a la formación de ambientes democráticos y plurales. A pesar de que no fueron variables específicas analizadas en la muestra, el análisis de algunas de las imágenes coinciden con lo encontrado por autores latinoamericanos con respecto al uso del meme como elementos culturales, visuales y humorísticos que contravienen el poder político, pero que perpetúan la violencia, el racismo o el clasismo, utilizando como escudo el humor y la sátira. Esta conclusión es un poco preocupante en contextos polarizados e históricamente violentos como el de Colombia, que se encuentra inmersa en procesos políticos de transición hacia la pacificación.

La investigación destaca las características meméticas que generaron mayores interacciones entre los usuarios e incentivaron la expresión política online en torno a la disputa electoral colombiana de 2018. Por ejemplo, se evidencia que las imágenes fijas son más efectivas en la propagación de memes originales que buscan apelar a la creatividad de los usuarios sin necesidad de recurrir a la cultura popular. Además, el estudio permitió constatar que el uso de caracteres adicionales genera un amplio número de interacciones (retweets) en Twitter entre los usuarios e incentivan la expresión y el debate político online en segundas pantallas.

Este estudio también resalta los tipos de humor y el tipo de viralidad que los usuarios utilizan a la hora de enmarcar un candidato. Por ejemplo, se revela que la superioridad es el tipo de humor más utilizado para enmarcar a un candidato ideal, en este caso Gustavo Petro, quien se mostraba como el "ganador" de los debates en Twitter seguido por Humberto de la Calle; mientras que el juego fue el tipo de humor más efectivo para enmarcar a un candidato perdedor, en este caso, Iván Duque. Vargas Lleras también fue uno de los grandes perdedores en Twitter y fue enmarcado dentro de la masculinidad defectuosa como uno de los tipos de humor menos favorable hacia un candidato. A su vez, el estudio evidenció que la viralidad simple es la más utilizada por los usuarios digitales para explicar en una imagen fija una situación o una idea, que puede ser compleja; en la mayoría de los casos, para presentar ideas meméticas que buscaban generar conversación y controversia sobre candidatos perdedores en situaciones embarazosas o que hacían referencia a temáticas de política o corrupción. Además, el estudio demostró que, si bien la viralidad simple fue la más usada, es la viralidad concreta la que permite más retweets ya que fomenta explicaciones (en el texto del tweet) más concretas, aún cuando las imágenes sean abstractas y no reflejen directamente a los candidatos.

El estudio presenta limitaciones en términos de la representatividad de la muestra, dado que fue seleccionada manualmente. El uso de un software analítico que tuviera acceso a la base de datos completa de Twitter podría haber sido más acertado y exhaustivo al momento de agrupar específicamente un perfil socio-demográfico de las audiencias, así como de 
reunir automáticamente un cuerpo memético más robusto. En cuanto a futuros desarrollos a esta investigación, es plausible la incorporación de instrumentos cualitativos que permitan comprender y analizar más aspectos sobre las narrativas que se utilizan en los memes.

\section{Referencias bibliográficas}

- Abdi, H., \& Williams, L. J. (2010). Tukey's honestly significant difference (HSD) test. Encyclopedia of Research Design. Thousand Oaks, CA: Sage, 1-5.

- Adegoju, A., \& Oyebode, O. (2015). “Humour as Discursive Practice in Nigeria’s 2015 Presidential Election Online Campaign Discourse.” Discourse Studies, 17(6), 643-662.

- Aruguete, N. (2011). “Framing. La Perspectiva de las Noticias. La Trama de la Comunicación”. Anuario del Departamento de Ciencias de la Comunicación, 15: 67-80. Rosario, UNR Editora.

- Bañuelos-Capistrán, J. y Cerrillo-Garnica, O. (2020). La construcción de la imagen pública de Hugo López-Gatell a través del meme en el contexto de la pandemia de COVID-19. Virtualis, 11 (21), 137-158

- Bauckhage, C. (2011). Insights into internet Memes. Proceedings of the Fifth International AAAI Conference on Weblogs and Social Media. Barcelona. Disponible en http://www.aaai.org/ocs/index.php/ICWSM/ICWSM11/paper/view/2757/3304

- Chavarría-Cruz, A. (2020). El meme en Internet: el Skin-O-Meter como estrategia del dispositivo del poder. Virtualis, 11(21), 159-178.

- Collado Campos, A.N. (2020). Participación política de usuarios de Internet a través de memes: Anotaciones sobre el caso de Enrique Peña Nieto. Argumentos, Estudios críticos de la sociedad, 94. https://doi.org/10.24275/uamxoc-dcsh/argumentos/202094-11

- Dahlgren, P. (2009). Media and Political Engagement: Citizens, Communication, and Democracy. Cambridge: Cambridge University Press.

- Dawkins, R. (2000). El Gen Egoísta. Barcelona: Salvat.

- De Vreese, C. H. (2005). “News framing: Theory and Typology.” Information Design Journal \& Document Design, 13(1): 51-62.

- Du Preez, A., \& Lombard, E. (2014). "The Role of Memes in the Construction of Facebook Personae." Communication, 40(3), 253-270.

- Eizaguirre, L. E. (2016). Memecracia. “Los Virales Que Nos Gobiernan. Cómo las Ideas Contagiosas Usan Internet para Manipular a la Gente." Estudios Sobre el Mensaje Periodístico, 22(2), 1257.

- Espinosa, F. G., Vargas, E. H., \& Franco, A. V. (2014). “Análisis Crítico del Discurso de los 
Alusivos al Debate sobre Paramilitarismo del Congreso de la República de Colombia”. Nexus, 70-94.

- Field, A. (2013). Discovering Statistics Using IBM SPSS Statistics (4th ed.). London, UK: Sage.

- Foster, B. (2014). It's All in a Meme: A Content Analysis of Memes Posted to 2012 Presidential Election Facebook Pages. Master's Thesis dissertation. University of Arkansas.

- Freelon, D., \& Karpf, D. (2015). “Of Big Birds and Bayonets: Hybrid Twitter Interactivity in the 2012 Presidential Debates.” Information, Communication \& Society, 18(4), 390-406.

- García-González, L. \& Bailey Guedes, O. (2020). Memes de Internet y violencia de género a partir de la protesta feminista \#UnVioladorEnTuCamino. Virtualis, 11(21), 109-136.

- Giglietto, F., \& Selva, D. (2014). "Second Screen and Participation: A Content Analysis on a Full Season Dataset of Tweets." Journal of Communication, 64(2), 260-77.

- Grabe, M. E., \& Bucy, E. P. (2009). Image bite politics: News and the visual framing of elections, Oxford, UK: Oxford University Press.

- Gutiérrez-Vidrio, S. \& Reyna-Ruiz, M. (2020). Los memes en la política: primer debate de la contienda presidencial mexicana 2018. Virtualis, 11 (21), 89-108.

- Heath, C., \& Heath, D. (2007). Made to Stick: Why Some Ideas Survive and Others Die. New York, NY: Random House.

- Huerta, D. G. (2014). “Las imágenes macro y los memes de internet: posibilidades de estudio desde las teorías de la comunicación.” PAAKAT: Revista de Tecnología y Sociedad, 4(7), 11.

- Jenkins, H., Ford, S., \& Green, J. (2013). Spreadable Media: Creating Value and Meaning in a Networked Culture. New York: NYU Press.

- Jurgenson, N. (2012). Speaking in Memes. The New Inquiry. Recuperado de:

http://the-newinquiry.com/essays/speaking-in-memes/

- Knobel, M., \& Lankshear, C. (2007). “Online Memes, Affinities, and Cultural Production.” A New Literacies Sampler, 29, 199-227.

- Kress, G., \& Van Leeuwen, T. V. (2001). Multimodal Discourse: The Modes and Media of Contemporary Communication. London, UK: Arnold.

- Krippendorff, K. (2018). Content Analysis: An Introduction to Its Methodology. London, UK: Sage.

- Kuntsman, A., \& Raji, S. (2012). “Israelis and Iranians, Get A Room!: Love, Hate, and Transnational Politics from the 'Israel Loves Iran' and 'Iran Loves Israel' Facebook 
Campaigns." Journal of Middle East Women's Studies, 8(3), 143-154.

- Malin B (2005) American Masculinity under Clinton: Popular Media and the Nineties 'Crisis of Masculinity'. New York, NY: Peter Lang.

- Marchetti, R., \& Ceccobelli, D. (2016). "Twitter and Television in a Hybrid Media System: The 2013 Italian Election Campaign." Journalism Practice, 10(5), 626-644.

- Mercado, A. \& Scargiali, E. (2020) Las derechas hechas meme en Argentina y Brasil (2015-2019): un análisis sobre los contenidos de humor político en el contexto de gobiernos conservadores. Centro de Estudios en Diseño y Comunicación. 112, 279-294.

- Milner, R. M. (2013). "Pop Polyvocality: Internet Memes, Public Participation, and the Occupy Wall Street Movement.” International Journal of Communication, (7), 2357-2390

- Pastene, M. A., Pérez, O. I., \& Haquin, D. M. (2017). “Enfoque multimodal: los recursos semióticos visuales para la mediación pedagógica en un aula de estudiantes sordos." Revista Electrónica Diálogos Educativos, 15(29), 34-53.

- Pérez Salazar, G. (2020). El meme en internet. Virtualis, 11 (21), i-vii.

- Ramírez-Monge, D. \& Siles, I. (2020). Prácticas y dinámicas de creación de memes en Costa Rica. Virtualis,11(21)., 68-88.

- Ratkiewicz, J., Conover, M., Meiss, M. R., Gonçalves, B., Flammini, A., \& Menczer, F. (2011). Detecting and Tracking Political Abuse in Social Media. ICWSM, 11, 297-304.

- Reese, S. (2001). “Framing public life: a bridging model for media research" (p. 7-31). En: Reese, S; Gandy, Oscar; Grant, A. (eds.). Framing public life: perspectives on media and our understanding of the social world. Mahwah, NJ: Lawrence Erlbaum Associates.

- Robles, M. (Sin fecha). Análisis de varianza (ANOVA) en la investigación. Boletín de investigación Postgrado, consultado en: 18 de abril de 2019. Recuperado de http://www11.urbe.edu/boletines/postgrado/?p=1417

- Ross, A. S., \& Rivers, D. J. (2017). Digital cultures of political participation: Internet memes and the discursive delegitimization of the 2016 US Presidential candidates. Discourse, Context \& Media, 16, 1-11.

- Segev, E., Nissenbaum, A., Stolero, N., \& Shifman, L. (2015). "Families and Networks of Internet Memes: The Relationship Between Cohesiveness, Uniqueness, and Quiddity Concreteness." Journal of Computer-Mediated Communication, 20(4), 417-433.

- Shifman, L. (2012). “An anatomy of a YouTube Meme.” New Media \& Society, 14(2), 187-203.

- Shifman, L. (2013). "Memes in a Digital World: Reconciling with a Conceptual Troublemaker." Journal of Computer-Mediated Communication, 18(3), 362-377. 
- We are Social. (2020). Global Digital Report 2020. Recuperado de https://digitalreport.wearesocial.com/

- Yang, F. (2016). “Rethinking China's Internet Censorship: The Practice of Recoding and the Politics of Visibility." New Media \& Society, 18(7), 1364-1381.

\section{Sobre los autores}

William David Suárez Acosta: Magíster en Periodismo y Comunicación Digital de la Universidad de La Sabana. Correo:williamsuac@gmail.com

Víctor García-Perdomo: Director del Doctorado en Comunicación de la Universidad de la Sabana. Ph.D. en Periodismo por la Universidad de Texas en Austin, Correo:

victor.garcia2@unisabana.edu.co 